\title{
Imagining fictious childhood events: The role of individual differences in imagination inflation
}

Citation for published version (APA):

Horselenberg, R., Merckelbach, H. L. G. J., Muris, P. E. H. M., Rassin, E. G. C., Sijsenaar, E., \& Spaan, V. J. E. (2000). Imagining fictious childhood events: The role of individual differences in imagination inflation. Clinical Psychology \& Psychotherapy, 7(2), 128-137. https://doi.org/10.1002/(SICl) 10990879(200005)7:2<128::AID-CPP238>3.0.CO;2-Q

Document status and date:

Published: 01/01/2000

DOI:

10.1002/(SICI)1099-0879(200005)7:2<128::AID-CPP238>3.0.CO;2-Q

Document Version:

Publisher's PDF, also known as Version of record

\section{Please check the document version of this publication:}

- A submitted manuscript is the version of the article upon submission and before peer-review. There can be important differences between the submitted version and the official published version of record.

People interested in the research are advised to contact the author for the final version of the publication, or visit the DOI to the publisher's website.

- The final author version and the galley proof are versions of the publication after peer review.

- The final published version features the final layout of the paper including the volume, issue and page numbers.

Link to publication

\footnotetext{
General rights rights.

- You may freely distribute the URL identifying the publication in the public portal. please follow below link for the End User Agreement:

www.umlib.nl/taverne-license

Take down policy

If you believe that this document breaches copyright please contact us at:

repository@maastrichtuniversity.nl

providing details and we will investigate your claim.
}

Copyright and moral rights for the publications made accessible in the public portal are retained by the authors and/or other copyright owners and it is a condition of accessing publications that users recognise and abide by the legal requirements associated with these

- Users may download and print one copy of any publication from the public portal for the purpose of private study or research.

- You may not further distribute the material or use it for any profit-making activity or commercial gain

If the publication is distributed under the terms of Article $25 \mathrm{fa}$ of the Dutch Copyright Act, indicated by the "Taverne" license above, 


\title{
Imagining Fictitious Childhood Events: The Role of Individual Differences in Imagination Inflation
}

\author{
Robert Horselenberg*, Harald Merckelbach, \\ Peter Muris, Eric Rassin, Madelon Sijsenaar and \\ Victor Spaan \\ Maastricht University, The Netherlands
}

\begin{abstract}
Imagination inflation refers to the phenomenon that imagining a low probability childhood event promotes subjective confidence that the event actually happened. The present article describes two studies that addressed the issue of whether imagination inflation is related to certain personality characteristics (i.e. social desirability, imagery ability, and dissociation). In Study 1, students $(N=34)$ rated the probability of 60 childhood events. Four weeks later, they came to the laboratory and were asked to imagine four low-probability childhood events. Next, new confidence ratings of target (i.e. imagined) and control items were collected. Students also completed measures of social desirability, imagery ability, and dissociation. While a higher percentage of increased confidence ratings was found for target items than for control items, the size of this imagination inflation effect was modest. Only imagery ability was found to be related to imagination inflation in that individuals with better imagery abilities displayed a larger imagination inflation effect. The procedure of Study $2(N=45)$ closely followed that of Study 1, except that imagination of target items now had to be written down. Writing about a fictitious event generated a straightforward imagination inflation phenomenon, but this was not related to any of the personality characteristics. The discussion focuses on the extent to which imagination inflation may model therapy-induced false memories. Copyright (C) 2000 John Wiley \& Sons, Ltd.
\end{abstract}

\section{INTRODUCTION}

In their often cited study, Garry et al. (1996) claimed that pseudomemories might develop as a result of a simple imagination instruction. Garry and colleagues had participants rate the probability

* Correspondence to: Robert Horselenberg, Department of Psychology, Maastricht University, P.O. Box 616, 6200 MD, Maastricht, The Netherlands. E-mail: R.Horselenberg@ Psychology.Unimaas.nl of a large number of possible childhood experiences. Next, the authors selected events that received low subjective probability ratings. Two weeks later, participants were asked to create detailed images of some of these low-probability events. Finally, participants again rated how confident they were that the events had happened to them. Imagination of the low-probability items produced an increased confidence that these events did happen, a phenomenon that the authors termed imagination inflation. 
According to Garry et al. (1996; see also Paddock et al., 1998; Heaps and Nash, 1999), imagination inflation can best be interpreted in terms of a source-monitoring disruption. By this view, imagining a fictitious event increases familiarity with that event. To the extent that this increased familiarity is misattributed to the authenticity of the event, source-monitoring problems arise (Johnson, 1988; Koehler, 1991; Goff and Roediger, 1998), which may promote the subjective probability of imagined events.

In discussing the implication of their findings, Garry et al. (1996, p. 214) note that 'when a mental health professional repeatedly encourages a client to imagine an abusive childhood event, these imagination activities may unknowingly promote a greater belief that particular episodes occurred. The search for fact may create a fiction'. Two recent studies succeeded in replicating the imagination inflation phenomenon in undergraduate students (Paddock et al., 1998; Heaps and Nash, 1999). While this suggests that imagination inflation is a robust phenomenon, a number of issues can be raised that have to do with the origins and magnitude of this phenomenon. To begin with, it remains to be seen whether source-monitoring failures provide the most plausible explanation for imagination inflation. More specifically, one could argue that inflation of subjective confidence subsequent to imagination instructions is a function of participants' sensitivity to demand characteristics, i.e. their tendency to exhibit socially-desirable responses. This point is important because the literature on eyewitness memory suggests that acceptance of misleading information might be related to participants' eagerness to cooperate with the perceived purpose of the study (see for a review, Winograd et al., 1998). While it is true that recent experiments on individual differences in memory illusions failed to detect a connection between social desirability and memory distortion (Wilkinson and Hyman, 1998; Winograd et al., 1998), to the present authors' knowledge, none of the published imagination inflation studies looked at the potential influence of social desirability. Thus, the current studies sought to examine to what extent the magnitude of the imagination inflation phenomenon depends on participants' social desirability tendencies.

Secondly, inspired by previous work showing that people with stronger dissociative tendencies and/or better imagery abilities are more susceptible to develop pseudomemories in response to misleading prompts, recent imagination inflation studies have looked at trait dimensions related to dissociation and imagery vividness. Whereas these studies found dissociative tendencies to be positively and significantly correlated with imagination inflation (Paddock et al., 1998; Heaps and Nash, 1999), no evidence was found to suggest that individual differences in imagery vividness modulates this phenomenon (Heaps and Nash, 1999). However, the connection between dissociation and imagination inflation reported by Heaps and Nash (1999) and Paddock et al. (1998) needs to be replicated. For one thing, correlations between dissociation and imagination inflation were only moderate $(r=0.34$ and $r=0.32$, respectively). Also, the Heaps and Nash (1999) study relied on a non-standard instrument for measuring dissociative tendencies, while Paddock et al.'s (1998) findings are difficult to interpret because these authors correlated dissociative tendencies with residual imagination scores produced by a multiple regression analysis.

A third issue is that Garry et al. (1996) describe their findings in terms of percentages of participants with increased confidence ratings for imagined and control items. While the percentage of participants with increased confidence was reliably greater for imagined than for control items, it is not clear what the magnitude of this increased confidence was in terms of scale points. The replicational studies by Paddock et al. (1998, experiments 1 and 2) are subject to the same limitation. On the other hand, Heaps and Nash (1999) reported both percentages of participants with increased confidence and increases in scale points. For both parameters, significant imagination inflation effects were found, yet effect sizes seemed to be more substantial for percentages than for scale points (0.68 versus 0.44$)$. Obviously, the hypothesis that imagining fictitious events may elicit pseudomemories about these events would gain in strength if it could be shown that imaginative activities produce large shifts on subjective confidence scales.

A fourth issue is whether imagination inflation effects are restricted to those situations in which participants engage in covert (i.e. silent) imagination of low probability events. More specifically, the question arises whether such effects may also be obtained with more therapeutically relevant techniques such as writing exercises.

With the aforementioned issues in mind, the present studies explored whether imagination inflation phenomena are related to certain personality traits (i.e. social desirability, imagery ability, and dissociation). In addition, an attempt 
was made to determine the magnitude of this phenomenon in terms of scale point shifts. In Study 1 , the imagination procedure closely followed that of Garry et al. (1996). In Study 2, a writing procedure was employed to elicit imagination inflation.

\section{STUDY 1}

\section{Method}

\section{Participants}

The final sample (see below) consisted of 34 psychology undergraduates (29 women) who volunteered to participate in study 1 . Their mean age was 20 years ( $S D=4.4$ years; range: $17-43$ years). Participants were paid for their participation.

\section{Materials}

A translated and adapted version of Garry et al.'s (1996) Life Events Inventory (LEI) was used in the current study. This LEI version $(\alpha=0.82)$ lists 60 items each describing a discrete childhood event that could have happened. Examples are: 'Broke a window with my hand', and 'Found a silver ring'. Respondents indicated on 7-point Likert scales how confident they were that the events happened to them before the age of 10 years $(1=$ 'definitely did not happen'; 7 = 'definitely did happen'). Participants also completed widely used Dutch translations of the Social Desirability Scale (SDS; Crowne and Marlow, 1964), the Questionnaire upon Mental Imagery (QMI; Sheehan, 1967), and the Dissociative Experiences Scale (DES; Bernstein and Putnam, 1986).

The SDS $(\alpha=0.36)$ consists of 33 true/false items (e.g. 'I never hesitate to help someone who is in distress') and is commonly used to measure the tendency to provide socially desirable responses across many situations. The low Cronbach alpha reflects the relatively broad range of situations that the SDS samples.

The QMI $(\alpha=0.91)$ is a 35-item self-report instrument that aims at measuring individual differences in imagery ability. Examples are 'How vividly and lively can you imagine the taste of salt' and 'How vividly and lively can you imagine the sensation of a soar throat'. Participants indicate on 7 -point Likert scales $(1=$ 'as perfectly clear as true'; $7=$ 'I think about it, but I cannot imagine it') how vividly and lively they can imagine each item. A low overall score implies excellent imagery ability.

The DES $(\alpha=0.93)$ consists of 28 items that per- tain to dissociative phenomena (e.g. feelings of derealization, depersonalization, disturbances in memory). Respondents indicate on 100-mm Visual Analogue Scales (VASs: 0 = 'not at all'; $100=$ 'very much') the frequency with which they experience these symptoms. Scores on the individual items are averaged to obtain a total DES score. The higher the total DES score, the stronger the dissociative tendencies.

\section{Procedure}

Eighty-two psychology undergraduates at Maastricht University completed the LEI. Next, a selection of items and participants was made. First, mean confidence score per item $(N=60)$ on the LEI was calculated and only those items that had average scores between 2 and 4 were selected. Additionally, only participants who did not have the maximum score (7) on one of the selected items were invited to participate in the experiment. This procedure resulted in a pool of eight LEI events and 34 participants. The experiment proper took place 4 weeks after LEI (LEI1) data had been collected during regular classes.

Upon arrival in the laboratory, participants completed the SDS. Next, they were told that the experiment was about individual differences in imagery ability. This was followed by an imagination task that involved four pre-selected LEI items (e.g. 'You found a beautiful silver ring'). The other four selected items served as control items (see below). Imagination and control items were counterbalanced across participants. That is, imagination items of one half of the participants served as control items for the other half and vice versa. Imagination instructions given to the participants closely followed those of Garry et al. (1996). Thus, the experimenter introduced each imagination item by reading a few sentences describing the context of the event (e.g. 'You're playing outside the house. Your mother just told you that within half an hour, dinner will be ready'). Participants were given 20 to $60 \mathrm{~s}$ to imagine this context. Subsequently, they answered a set of questions that pertained to their imaginations (e.g. 'With whom are you playing?'; 'Is it evening?'). The purpose of these questions was to encourage participants to elaborate their fantasy. The experimenter then read the pertinent part of the event that corresponded to the selected LEI item (e.g. 'As you are playing outside, your attention is attracted by a glistening object lying on the ground. You pick it up; it's a beautiful silver ring') and participants were again instructed to imagine 
this as completely as possible. Following this, participants answered some questions about the event (e.g. 'What will you do with the ring'). Each of the four imagination items was subjected to this procedure. Next, participants completed the QMI and DES. Finally, participants filled out the original LEI (LEI2). When a subject noticed that $\mathrm{s} /$ he had already completed this list, the experimenter said that the other LEI (LEI1) had been lost.

\section{Data Analysis}

Changes in subjective confidence from LEI1 (baseline) to LEI2 (post-experimental) for the imagination items were compared to those for matched control items. This was done in three different ways. First, the approach of Garry et al. (1996) was followed which consists of calculating for each imagination and control item the percentage of participants with increased, decreased, or unchanged probability ratings. Second, as this approach is not informative about the magnitude of subjective probability changes, a 2 (LEI1 versus LEI2) $\times 2$ (imagination versus control items) analysis of variance (ANOVA), with both factors being repeated measures, was performed on the subjective probability data. Third, Pearson productmoment correlations were computed between imagination inflation effects and individual difference measures (i.e. SDS, QMI, and DES).

\section{Results}

Figure 1 shows percentages of participants with increased, decreased, and unchanged subjective probability ratings for imagination and control items. Paired $t$-tests (with items as cases) revealed no difference between imagination and control items with regard to percentage decreased ratings $(t(7)<1.0)$. However, percentage of unchanged ratings were higher for control items than for imagined items $(t(7)=-1.90, p=0.05)$. In

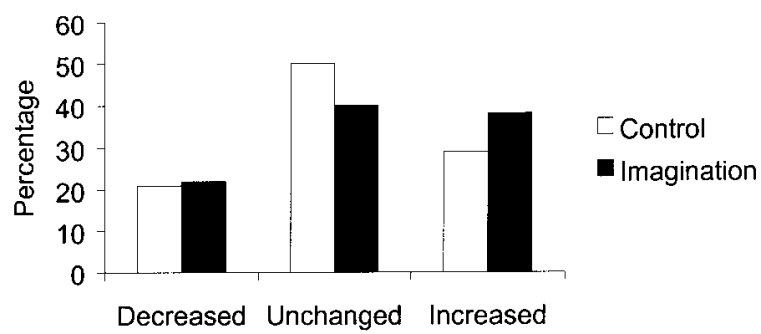

Figure 1. Mean percentages of participants $(N=34)$ with decreased, unchanged, and increased probability ratings for control and imagination items
Table 1. Mean subjective probability scores of participants $(N=34)$ on pre- and post-experimental imagination and control items of the life event inventory (LEI). Standard deviations are given in parentheses

\begin{tabular}{lcc}
\hline & Imagination items & Control items \\
\hline LEI1 & $2.42(0.85)$ & $2.43(1.01)$ \\
LEI2 & $2.79(0.95)$ & $2.70(0.74)$ \\
\hline
\end{tabular}

LEI1 is pre-experimental LEI; LEI2 is post-experimental LEI.

addition, imagination items tended to have a higher percentage of increased confidence ratings than control items. While this difference reached only borderline significance $(t(7)=1.62, p=0.07)$, the effect size was large $(r=0.52)$ and corresponded to that reported by others (e.g. Clancy et al., 2000).

Mean probability ratings for imagination and control items on LEI1 and LEI2 are shown in Table 1. The ANOVA yielded a significant main effect of LEI $(F(1,33)=7.21, p=0.01)$, which indicates a robust repetition effect. That is, irrespective of imagination, asking twice about the same events increased the subjective probability of these events. Neither the main effect of imagination, nor the critical interaction of LEI and imagination reached significance: both Fs $(1,33)<1.0$. Thus, the ANOVA yielded no evidence for an imagination inflation effect in terms of scale point shifts.

Mean scores on the SDS, DES, and QMI were $16.0 \quad(\mathrm{SD}=4.2), \quad 25.0 \quad(\mathrm{SD}=14.1), \quad$ and 88.9 $(\mathrm{SD}=22.8)$, respectively. It should be noted that these means are quite similar to the mean scores of undergraduate samples reported in other studies (e.g. Hyman and Billings, 1998; Aleman et al., 1999; Merckelbach et al., 2000). In order to explore possible links between these measures and imagination inflation, an index of imagination inflation was calculated by subtracting the change in ratings on control items from that on imagination items. This index provides the best estimate of imagination inflation as it controls for repetition effects. Next, Pearson product-moment correlations were computed between imagination inflation and personality traits. There was no correlation between imagination inflation and the tendency to give socially-desirable answers $(r=0.04)$. Neither was there a connection between imagination inflation and dissociative tendencies $(r=-0.03)$. The only correlation that attained significance was that between imagination inflation and imagery ability: $r=-0.34, p=0.05$. Note that the correlation was in the expected direction. That is, the higher the 
imagery ability (i.e. lower QMI scores), the stronger the imagination inflation effect.

\section{DISCUSSION}

The results of Study 1 can be summarized as follows. To begin with, the imagination inflation phenomenon described by Garry et al. (1996) was partially replicated. That is, the percentage of participants with increased subjective probability ratings tended to be higher for imagination items than for control items, while the percentage of unchanged probability ratings was higher for control than for imagination items. Second, when the magnitude of this effect (i.e. mean scale point changes rather than percentages of participants with increased confidence ratings) was taken into account, no convincing evidence for an imagination inflation phenomenon was found. At this level of analysis, only a repetition effect attained significance irrespective of the imagination manipulation, participants gave higher subjective probability ratings on the post-experimental LEI (LEI2) than on the pre-experimental LEI (LEI1). Third, at the within-subjects level, imagination inflation was not related to social desirability or dissociative tendencies. Yet, there was a significant though modest connection between imagery ability and imagination inflation.

In line with previous studies (Garry et al., 1996; Paddock et al., 1998; Heaps and Nash, 1999), the current results indicate that imagining low-probability events enhances confidence that the events had in fact occurred. Meanwhile, the magnitude of this effect appears to be small when one looks at scale point shifts rather than percentages of participants. This is reminiscent of Heaps and Nash's (1999) finding that effect sizes of imagination inflation are higher for percentages than for scale values. Does this mean that the practical (e.g. clinical) implications of imagination inflation are limited? Not necessarily. One could argue that imagination inflation, though fairly tame in the laboratory, might conceivably create powerful effects in those clinical settings where imagination exercises are carried out repeatedly and are aimed at ambiguous autobiographical events. Support for this line of reasoning comes from recent work of Goff and Roediger (1998). These authors noted that when participants imagine performing actions (e.g. 'bounce the ball'), they subsequently remember that they had actually carried out these actions and this effect increases with the number of imagination exercises.

The present data show that shifts in subjective confidence ratings of imagination items are not controlled by social desirability tendencies. This makes an interpretation of imagination inflation in terms of demand characteristics and social desirability less likely. In contrast, imagery vividness was found to be linked to imagination inflation. While this result is difficult to reconcile with Heaps and Nash's (1999) failure to detect an association between imagery ability and imagination inflation $(r=-0.06)$, it is in line with earlier studies showing that individuals with vivid imagery are more likely to make source-monitoring errors (Dobson and Markham, 1993) and to produce false recognition responses on word list tasks (Wilkinson and Hyman, 1998; Winograd et al., 1998). In more general terms, these studies converge upon the notion that persons with good imaginary abilities are more susceptible to memory illusions.

Unlike previous imagination inflation studies (Paddock et al., 1998; Heaps and Nash, 1999), we were unable to find a correlation between dissociative tendencies and imagination inflation. We have no obvious explanation for this discrepancy, except that, as noted in the Introduction, previous studies reported relatively moderate correlations and relied on operationalizations of dissociation and imagination inflation that are not particularly straightforward. As an aside, it should be noted that in the domain of memory illusions, a number of close-up studies specifically addressed the connection between dissociation and pseudomemories. Many of them failed to find such a connection between these two parameters (e.g. Platt et al., 1998; Mazzoni et al., 1999; Spanos et al., 1999). Perhaps then, dissociative tendencies are only a weak predictor of memory illusions and it requires considerable statistical power to demonstrate such a connection.

The question arises why the imagination inflation phenomenon found in the present study remained a moderate effect. There are two possible reasons for this. First, participants' imaginations were based on scenarios developed by the researchers. From a social-psychological point of view, such an approach cannot be expected to induce strong commitments of participants to their imaginations. Writing about a fictitious event might provide a much stronger manipulation (e.g. Spanos, 1996). A second factor that may have contributed to the fragile nature of the imagination inflation effect found in Study 1 is that the post- 
experimental LEI items were identical to the baseline LEI items. To the extent that participants want to make a consistent impression in their answers to the LEI items, this may have counteracted imagination inflation effects.

With these two issues in mind, Study 2 was conducted. Study 2 relied on an imagination inflation task that required a more active involvement of the participant. More specifically, a writing exercise was used. Thus, participants were instructed to write brief, but plausible stories about low-probability LEI events. Next, participants completed a post-experimental LEI (LEI2) that also included paraphrased versions of the pre-experimental imagination items. These additional items were included to reduce consistency tendencies.

\section{STUDY 2}

\section{Method}

\section{Participants}

Forty-five participants (30 women) participated in Study 2. Their mean age was 17 years $(S D=1.1$ years; range: $16-20$ years). Some participants were psychology undergraduates, but the majority of them were high school students recruited through advertisement in a local paper. Participants received a small financial compensation for their participation.

\section{Material}

Two weeks before the experiment took place, participants completed the LEI $(\alpha=0.83$; see Study $1)$. For practical reasons, the procedure of calibrating items for each participant deviated from that in Study 1. Most importantly, the sample in Study 2 was too small to allow selection of items on the basis of excluding participants. Therefore, items that had an average score between 2 and 4 in Study 1 were selected (see for a similar procedure, Paddock et al., 1998). This resulted in a pool of 12 possible imagination items with an average subjective probability rating of $2.2(\mathrm{SD}=1.2)$. From this pool, the experimenter selected four imagination items for each participant individually, using the criterion that none of the selected imagination items had a score of 6 or higher for that particular participant. Selection of control items from the pool of 48 remaining LEI1 items took place after the experiment. Control items were matched on mean pre-experimental subjective probability ratings assigned to the imagination items. As in Study 1, participants also completed the SDS $(\alpha=0.43)$, DES $(\alpha=0.95)$, and QMI $(\alpha=0.87)$.

\section{Procedure}

Two weeks after they had completed the LEI at home (LEI1), participants were invited to come to the laboratory. Participants were told that the experimenters were interested in creative writing. They were encouraged to imagine the pre-selected items and write their imaginations down. More specifically, each imagination trial started with a card on which the pertinent item was printed. The instruction was as follows: 'Try to imagine yourself actually experiencing the event you have just read. Experience this imaginary event as vividly and fully as you can. Write your imaginations down on the piece of paper in front of you. Describe as vividly and fully as possible all your imaginations'. This instruction was repeated for each imagination item. Following the imagination trials, participants completed the SDS, DES and QMI. Finally, the LEI was administered for a second time (LEI2). Twelve items were added to the LEI2. These items were paraphrases of the 12 potential imagination items and were positioned in such way that they preceded the original imagination items. Examples of paraphrased items are 'I took something from a store without paying for it' (original item: 'I stole sweets in a shop') and 'I said to my parents that I didn't feel good, so I didn't have to go for a school exam' (original item: 'I pretended to be sick, so I didn't have to go to school'). When participants indicated that they had already completed the LEI, the experimenter replied that they initially had received the wrong version of the questionnaire.

\section{Results}

Following Garry et al. (1996), percentages of participants with increased, decreased, and unchanged probability ratings were calculated for imagination and control items, separately. However, given the different procedure of selecting imagination and control items, paired $t$-test would be inappropriate for the data obtained in this study. Therefore, chi-square tests were carried out. Imagination and control items did not differ with regard to percentage of participants with decreased probability ratings (18.3 and 20.6\%, respectively; $\left.\chi^{2}(1)=0.28, p=0.69\right)$. Yet, imagination items had a lower percentage of participants with unchanged ratings than control items (43.9 and $62.2 \%$, respectively; $\chi^{2}(1)=12.15, p=0.001$ ), while the reverse was true for the percentage of 
Table 2. Mean subjective probability scores of participants $(N=45)$ on pre- and post-experimental imagination, paraphrased imagination items, and control items of the life event inventory (LEI). Standard deviations are given in parentheses

\begin{tabular}{lccc}
\hline & $\begin{array}{c}\text { Imagination } \\
\text { items }\end{array}$ & $\begin{array}{c}\text { Control } \\
\text { items }\end{array}$ & $\begin{array}{c}\text { Paraphrased } \\
\text { imagination items }\end{array}$ \\
\hline LEI1 & $2.20(0.78)$ & $2.22(1.21)$ & - \\
LEI2 & $2.71(1.17)$ & $2.20(1.10)$ & $3.95(1.02)$ \\
\hline
\end{tabular}

LEI1 is pre-experimental LEI; LEI2 is post-experimental LEI.

increased ratings (37.8 and $17.2 \%$, respectively; $\left.\chi^{2}(1)=19.07, p=0.001\right)$.

Average subjective probability ratings for imagination and control items on LEI1 and LEI2 are shown in Table 2 . A 2 (LEI1 versus LEI2) $\times 2$ (imagination versus control) ANOVA, with both factors being repeated measures, was performed on these data. This ANOVA yielded a significant main effect of imagination $(F(1,44)=6.94$, $p<0.05)$. Overall, imagination items had higher probability ratings than control items. Most importantly, the critical interaction of LEI and imagination reached significance $(F(1,44)=7.84, p<0.01)$, indicating a reliable imagination inflation effect. There was no significant repetition effect of LEI $(F(1,44)=2.01, p=0.16)$.

Mean scores on the SDS, DES, and QMI were highly comparable to those obtained in Study 1: 18.6 $(\mathrm{SD}=4.4), \quad 16.2 \quad(\mathrm{SD}=13.4), \quad$ and 92.7 $(\mathrm{SD}=18.6)$. There was no significant relation between imagination inflation (calculated as preto post-test changes on imagination items corrected for repetition effects on control items; see Study 1) and the tendency to give socially-desirable answers $(r=-0.20, p>0.10)$. Neither was there a connection between imagination inflation and dissociative tendencies $(r=-0.18)$. Curiously enough, the connection between imagination inflation and imagery ability found in Study 1 was not replicated in this study $(r=0.20)$.

The right-hand column of Table 2 shows mean confidence ratings of the paraphrased LEI2 items. Note that the paraphrased imagination items had a relatively high mean confidence rating, that is, a rating that exceeds the midpoint of the scale (i.e. 3.5). Subjective probability ratings of paraphrased imagination items were higher than those on LEI2 control items $(t(44)=-9.11, p<0.001)$ and also exceeded those on LEI2 imagination items $(t(44)=-5.66, p<0.001)$. These findings suggest that a straightforward imagination inflation effect occurred for the paraphrased imagination items. To explore whether imagination inflation for paraphrased items was related to SDS, DES, and QMI, imagination inflation was redefined as confidence changes from imagination items on LEI1 to paraphrased items on LEI2 corrected for changes on control items. However, no significant correlations were found between imagination inflation defined in this way and personality characteristics (all $r \mathrm{~s}$ $<0.20$, all $p$ s $>0.10$ ).

\section{DISCUSSION}

The findings of Study 2 can be summarized as follows. To begin with, writing about a fictitious event led to a reliable imagination inflation phenomenon, both in terms of percentages of participants with increasing confidence ratings and mean increases on the 7-point probability scale. Second, no evidence was found to suggest that this imagination inflation phenomenon is linked to social desirability characteristics. Neither were there indications that the phenomenon is linked to dissociative tendencies or imagery vividness. Third, imagination inflation was even more evident with paraphrased versions of the imagination items, suggesting that participants' tendency to respond in a consistent manner may, indeed, counteract the imagination inflation phenomenon.

Differences in sample characteristics and item selection preclude direct comparisons between Study 1 and Study 2. Nevertheless, results suggest that Study 2 demonstrated a much stronger version of the imagination inflation phenomenon than Study 1 . Thus, the present findings support Spanos' (1996) claim that writing about fictitious events may foster subjective confidence in those events (see also Destun and Kuiper, 1996). But why would writing about imaginations produce a more convincing imagination inflation phenomenon than does the sort of silent imagination exercise used in Study 1? Two possibilities suggest themselves. One is that writing produces a 'public record' (Spanos, 1996, p. 100). This, in turn, may create a stronger commitment than the silent imagination sessions of Study 1. Interestingly, effects of writing about counter-attitudinal beliefs have been well researched in social psychology. A number of studies on cognitive dissonance have demonstrated that when people are asked to write an essay about a counter-attitudinal view without being paid for this, they subsequently express more agreement with that view (e.g. Cohen, 1962). A second possi- 
bility has to do with a more technical issue, namely that the imagination procedure followed in Study 1 consisted of prompts formulated by the experimenters, while the procedure of Study 2 was not structured in this way. Thus, it may well be the case that the procedure of Study 2 allowed for more idiosyncratic and, therefore, more plausible imaginations.

As in Study 1, no evidence was found to support an interpretation of imagination inflation in terms of participants' sensitivity to experimental demands. In both studies, increases in confidence for imagination items were not related to participants' SDS scores. Accordingly, it is unlikely that imagination inflation is an artefact caused by participants' tendency to comply with the demands of the experiment. While Study 1 found a significant, though modest, connection between imagery ability and the imagination inflation phenomenon, such a connection was not replicated in Study 2. This implies that the correlation between imagination inflation and imagery vividness is not a robust one. On the other hand, like Study 1, Study 2 failed to obtain a significant correlation between dissociative tendencies and imagination inflation. We return to this issue in the general discussion.

Study 2 demonstrates that when paraphrased imagination items are employed, the imagination inflation effect is not only significant, but also crosses the midpoint of the confidence scale (i.e. 3.5). Perhaps, then, experimental set-ups that rely on identical pre- and post-experimental LEIs produce an underestimation of the imagination inflation phenomenon. Note, however, that the post-experimental LEI in the current study did not include paraphrases of control items. A more rigorous test of the idea that identical pre- and postexperimental LEIs induce consistency tendencies, thereby reducing imagination inflation effects, would involve direct comparisons between paraphrased control and imagination items. One could argue that the relatively high confidence ratings of paraphrased imagination items are simply the result of the fact that these items repeat the content of standard imagination items of LEI1. This would imply that the heightened probability ratings on paraphrases reflect a repetition effect. However, such an interpretation is flawed on several counts. First, it leaves unexplained why ratings on paraphrased items were quite high. The magnitude of the repetition effects is usually in the order of 0.3 scale points (e.g. Brown and Nix, 1996) which is considerably smaller than the 1.7 scale points increase found for paraphrases in the current study. Another problem with this explanation is that it is difficult to reconcile with the absence of a repetition-effect for control items (cf. above). Why would such an effect become manifest during LEI2 only for paraphrases of imagination items, but not for control items? After all, control items of LEI2 were identical to control items of LEI1, whereas paraphrases of LEI2 were just what they were: paraphrases. A related issue is that the LEI2 was designed in such a way that paraphrases preceded the pertinent imagination items. Consequently, an explanation in terms of repetition effects would dictate a huge confidence increase for the imagination items and a relatively small increase for the paraphrases. Yet, as a matter of fact, the opposite pattern occurred, which casts doubts on a repetition-effect account.

\section{GENERAL DISCUSSION}

Taken together, the present studies provide support for the idea that imagining a low-probability childhood event promotes subjective confidence in that event. In general, then, the current findings accord well with those reported by Garry et al. (1996), Heaps and Nash (1999), Paddock et al. (1998), and Clancy et al. (2000). It should be added, though, that the magnitude of this effect remained small in Study 1. A more convincing effect was obtained in Study 2, but here imagination was combined with writing exercises. This suggests that a single and covert act of imagination results in robust, but relatively small shifts of subjective confidence, while huge effects may be produced by writing imaginations down.

Plainly, the effects of writing an imagination down bears relevance to clinical settings. Over the past few years, writing exercises have become a common treatment intervention for individuals with traumatic experiences (e.g. Pennebaker, 1993; see also Littrell, 1998). The beneficial effects of this intervention on health parameters are well-established (e.g. Greenberg et al., 1996). However, writing exercises have also been advocated as a vehicle for memory recovery. For example, a survey among licensed psychotherapists conducted by Poole et al. (1995) revealed that a considerable percentage of surveyed psychotherapists had used journalling as a technique to help clients recover memories of sexual abuse. In their scholarly review on recovered memories, Lindsay and Read (1994, p. 301) noted that they were 'particularly con- 
cerned about cases in which the instructions for journalling suggest that writers should strive for a non-critical, stream-of-consciousness flow, writing down whatever comes to mind without stopping to evaluate it'. The results of Study 2 show that Lindsay and Read's concern is not misplaced.

Dissociative tendencies as indexed by the DES (Bernstein and Putnam, 1986) have been found to be linked to suggestibility (Merckelbach et al., 1998; Wolfradt and Meyer, 1998), fantasy proneness (Rauschenberg and Lynn, 1995; Merckelbach et al., 1999), and the propensity to develop pseudomemories (Hyman and Billings, 1998). There is also some evidence that dissociative tendencies may be related to imagination inflation (Paddock et al., 1998; Heaps and Nash, 1999; Clancy et al., 2000). From this perspective, it is surprising that the present studies failed to obtain significant correlations between dissociation and imagination inflation. We can only speculate about the reasons for these null findings. One possibility is that the relation between dissociative tendencies and memory distortions is not as impressive as some authors have suggested. This position is supported by the fact that a number of recent studies found no (Platt $e t$ al., 1998; Mazzoni et al., 1999; Spanos et al., 1999) or only a small (e.g. Eisen and Carlson, 1998) correlations between DES and the tendency to generate illusory memories. It is hard to escape the conclusion that broad trait measures of dissociative tendencies (e.g. DES) and imagery ability (e.g. QMI) provide only imperfect operationalizations of source-monitoring decisions involved in discriminating between real and pseudomemories. Therefore, future studies should carry out more fine-grained analyses to establish which aspects (e.g. subscales, factors) of dissociation and imagery ability tap source-monitoring aspects (see for an example, Wilkinson and Hyman, 1998).

Another possibility is that imagination inflation is a metamemory rather than a memory phenomenon. That is, it is conceivable that as a result of imagination exercise(s), people change their belief about the probability of target items but do not necessarily develop pseudomemories about these items. To the extent that individual differences in dissociation and imagery ability are linked to pseudomemories rather than metamemory beliefs, one would not expect to find strong correlations between imagination inflation and these personality traits. Clearly, this point warrants further study.

The present findings along with those of Garry et al. (1996), Goff and Roediger (1998), Heaps and
Nash (1999), Paddock et al. (1998) and Clancy et al. (2000) converge on the notion that imagination inflation is a real phenomenon that bears relevance to clinical practice. Obviously, the issue of what is inflated during imagination inflation requires further study. In addition, it would be worthwhile to run parametric studies that examine whether imagination inflation can, indeed, be maximalized with paraphrased items. In more general terms, the precise interplay between imagination inflation, source-monitoring decisions, and personality aspects awaits clarification.

\section{REFERENCES}

Aleman A, Boecker KB, de Haan EHF. 1999. Disposition towards hallucination and subjective versus objective vividness of imagery in normal subjects. Personality and Individual Differences 27: 707-714.

Bernstein EM, Putnam FW. 1986. Development, reliability and validity of a dissociation scale. Journal of Nervous and Mental Disease 174: 727-735.

Brown AS, Nix LA. 1996. Turning lies into truths: Referential validation of falsehoods. Journal of Experimental Psychology: Learning, Memory, and Cognition 22: 10881100.

Clancy SA, McNally RJ, Schacter DL. 2000. Effects of guided imagery on memory distortion in women reporting recovered memories of childhood sexual abuse. Journal of Traumatic Stress 11: 26-31.

Cohen AR. 1962. An experiment on small rewards for discrepant compliance and attitude change. In Explorations in Cognitive Dissonance, Brehm IJW, Cohen AR (eds). Wiley: New York; 73-78.

Crowne D, Marlow D. 1964. The Approval Motive. Wiley: New York.

Destun LM, Kuiper NA. 1996. Autobiographical memory and recovered memory therapy: Integrating cognitive, clinical, and individual difference perspectives. Clinical Psychology Review 16: 421-450.

Dobson M, Markham R. 1993. Imagery ability and source monitoring: Implication for eyewitness memory. British Journal of Psychology 32: 111-118.

Eisen ML, Carlson EB. 1998. Individual differences in suggestibility: Examining the influence of dissociation, absorption, and a history of childhood abuse. Applied Cognitive Psychology 12: S47-S61.

Garry M, Manning CG, Loftus EF, Sherman SJ. 1996. Imagination inflation: imagining a childhood event inflates confidence that it occurred. Psychonomic Bulletin E Review 3: 208-214.

Goff LM, Roediger HL. 1998. Imagination inflation for action events: Repeated imaginings lead to illusory recollections. Memory \& Cognition 26: 20-33.

Greenberg MA, Wortman CB, Stone AA. 1996. Emotional expression and physical health: Reviving traumatic memories or fostering self-regulation? Journal of Personality and Social Psychology 71: 588-602.

Heaps C, Nash M. 1999. Individual differences in imagin- 
ation inflation. Psychonomic Bulletin \& Review 6: 313318.

Hyman IE, Billings JF. 1998. Individual differences and false memories. Memory 6: 1-20.

Johnson MK. 1988. Reality monitoring: An experimental phenomenological approach. Journal of Experimental Psychology: General 117: 390-394.

Koehler DJ. 1991. Explanation, imagination, and confidence in judgement. Psychological Bulletin 110: 499537.

Lindsay DS, Read JD. 1994. Psychotherapy and memories of child sexual abuse: a cognitive perspective. Applied Cognitive Psychology 8: 281-338.

Littrell J. 1998. Is the re-experience of painful emotion therapeutic? Clinical Psychology Review 18: 71-102.

Loftus EF. 1996. Memory distortion and false memory creation. Bulletin of the American Academy of Psychiatry and Law 24: 281-295.

Mazzoni GAL, Loftus EF, Seitz A, Lynn SJ. 1999. Changing beliefs and memories through dream interpretation. Applied Cognitive Psychology 13: 125-144.

Merckelbach H, Muris P, Horselenberg R, Stougie S. 2000. Dissociative experiences, response bias, and fantasy-proneness in college students. Personality and Individual Differences 28: 49-58.

Merckelbach H, Muris P, Rassin E. 1999. Fantasy proneness and cognitive failures as correlates of dissociative experiences. Personality and Individual Differences 26: 961-967.

Merckelbach H, Muris P, Wessel I, van Koppen PJ. 1998. The Gudjonsson Suggestibility Scale (GSS): Further data on its reliability, validity, and metacognition correlates. Social Behavior and Personality 26: 203-210.

Paddock JR, Joseph AL, Chan FM, Terranova S, Manning C, Loftus EF. 1998. When guided visualization procedures may backfire: Imagination inflation and predicting individual differences in suggestibility. Applied Cognitive Psychology 12: S63-S75.
Pennebaker JW. 1993. Putting stress into words: Health, linguistic, and therapeutic implications. Behaviour Research and Therapy 31: 539-548.

Platt RD, Lacey SC, Iobst AD, Finkelman D. 1998. Absorption, dissociation, and fantasy-proneness as predictors of memory distortion in autobiographical and laboratory-generated memories. Applied Cognitive Psychology 12: S77-S89.

Poole DA, Lindsay DS, Memon A, Bull R. 1995. Psychotherapy and the recovery of memories of childhood sexual abuse: U.S. and British practitioners' beliefs, practices, and experiences. Journal of Consulting and Clinical Psychology 63: 426-437.

Rauschenberg SL, Lynn SJ. 1995. Fantasy proneness, DSM-III-R axis I psychopathology, and dissociation. Journal of Abnormal Psychology 104: 373-380.

Sheehan PW. 1967. A shortened form of Bett's questionnaire upon mental imagery. Journal of Clinical Psychology 23: 386-389.

Spanos NP. 1996. Multiple Identities and False Memories: A Sociocognitive Perspective. American Psychological Association: Washington, DC.

Spanos NP, Burgess, Burgess, Samuels, Blois. 1999. Creating false memories of infancy with hypnotic and non-hypnotic procedures. Applied Cognitive Psychology 13: 201-218.

Wilkinson C, Hyman IE. 1998. Individual differences related to two types of memory errors: Word lists may not generalize to autobiographical memory. Applied Cognitive Psychology 12: S29-S46.

Winograd E, Peluso JP, Glover TA. 1998. Individual differences in susceptibility to memory illusions. Applied Cognitive Psychology 12: S5-S27.

Wolfradt U, Meyer T. 1998. Interrogative suggestibility, anxiety, and dissociation among anxious patients and normal controls. Personality and Individual Differences 25: $425-432$. 